\title{
REFLEXÃO SOBRE A CULTURA BRASILEIRA E O EFEITO DO INFLUXO EXTERNO
}

\section{A REFLECTION ON BRAZILIAN CULTURE AND THE EFFECT OF FOREING CULTURAL INFLUENCE}

\author{
Rosanne Bezerra de Araújo \\ Universidade Federal do Rio Grande do Norte \\ Jorge Witt de Mendonça Junior ${ }^{2}$ \\ Universidade do Estado do Rio Grande do Norte
}

\begin{abstract}
RESUMO
Este ensaio apresenta uma reflexão sobre a crítica de Antonio Candido e Roberto Schwarz a respeito da cultura brasileira que sofre o efeito da ideologia estrangeira que molda a nossa identidade. Para tanto, estabelecemos relações entre dois poemas, um de Ascenso Ferreira, "Oropa, França e Bahia", e outro de Carlos Drummond de Andrade, "Europa, França e Bahia". Ambos repetem a frase também presente na obra Macunaima, de Mário de Andrade. Nosso método de pesquisa segue a crítica integrativa de Antonio Candido, pois investigamos os poemas e o trecho de Macunaíma, observando o aspecto social e cultural da construção dos textos. $\mathrm{O}$ resultado deste estudo nos revela que os textos literários, aqui comentados, apresentam uma sátira do efeito do influxo externo na cultura brasileira.
\end{abstract}

PALAVRAS-CHAVE: Ideologia; Influxo externo; Crítica dialética.

\begin{abstract}
This essay presents a reflection on the criticism of Antonio Candido and Roberto Schwarz regarding Brazilian culture that suffers the effect of Brazilian identity being shaped by foreign ideology. To this end, we highlight connections between the two poems, "Oropa, França e Bahia" by Ascenso Ferreira, and "Europa, França e Bahia", by Carlos Drummond de Andrade. Both poems repeat the title phrase, which is also present in the novel, Macunaima, by Mário de Andrade. Our research method follows the integrative critique of Antonio Candido, as we investigate the poems and the excerpt from Macunaima, observing social and cultural aspects of the construction of the texts. Results of the study reveal that the literary texts, discussed here, present a satire on the effect of foreign cultural influence in Brazil.
\end{abstract}

KEYWORDS: Ideology; Foreign cultural influence; Dialectical criticism.

\section{INTRODUÇÃO}

No presente ensaio procuramos desenvolver uma crítica da cultura brasileira, fundamentada no pensamento de alguns estudiosos como Antonio Candido (1918-2017), Roberto Schwarz (1938-) e Pascale Casanova (1959-). Como sabemos, o Brasil sempre sofreu o

\footnotetext{
${ }^{1}$ Doutora em Literatura Comparada. Professora do Departamento de Línguas e Literaturas Estrangeiras Modernas e do Programa de Pós-graduação em Estudos da Linguagem da UFRN. E-mail: rosanne.araujo@terra.com.br.

2 Mestre em Literatura Comparada pelo Programa de Pós-graduação em Estudos da Linguagem da UFRN. Professor da Faculdade de Letras e Artes da UERN. E-mail: witt.junior@gmail.com.
} 
efeito do influxo externo. Mesmo após a independência, a influência do estrangeiro permanece um elemento chave de nossa cultura, juntamente com o efeito do capitalismo mundial e sua relação com a força política do neoliberalismo que abocanha países em desenvolvimento como o Brasil. É fato que nós, brasileiros, como bem afirma Schwarz em "Nacional por subtração", valorizamos tudo o que é estrangeiro e seguimos caminhando desencontrados com a nossa realidade nacional. Somos moldados pelo modelo europeu, seja na cultura, na economia e na política. Essa reprodução ideológica do estrangeiro naturalmente repete-se no campo das artes e da literatura. Conforme revela o famoso poema de Ascenso Ferreira (1895-1965), "Oropa, França e Bahia", sempre predominou o pensamento de que o que vem de fora é melhor, como demonstra a curiosidade da mulata Maria, personagem de seu poema, diante das naus estrangeiras. Para problematizar a questão do influxo externo em nossa cultura/literatura, pretendemos comentar alguns trechos de "Oropa, França e Bahia", seguido da leitura do poema "Europa, França e Bahia" de Carlos Drummond de Andrade (1925-1987) e da frase "Oropa, França e Bahia” na prosa de Mário de Andrade (1893-1945).

\section{O desacerto de ideias afastadas da realidade brasileira}

Ao refletir sobre o Brasil na contemporaneidade, inevitavelmente surge o desejo e a necessidade de percorrer, ainda que de forma sucinta, a historiografia brasileira desde o século XIX. Seguindo o pensamento de Sergio Buarque de Holanda, Antonio Candido e outros críticos, Roberto Schwarz observa que a clamada Independência do Brasil foi feita em nome de ideias francesas, inglesas e americanas, permeadas do pensamento liberal. Ironicamente, esse conjunto ideológico que importamos, entrava em contradição com os defensores e praticantes da escravidão no Brasil.

Em seu ensaio, "As ideias fora do lugar", Schwarz revela a incompatibilidade entre a escravidão na sociedade brasileira e o pensamento liberal importado da Europa. Essa desproporção de ideias é chamada pelo escritor de "comédia ideológica". Desproporções, disparates, contradições e anacronismos moldaram a modernidade brasileira. Seja na economia, na política, na literatura ou na arquitetura, nossa cultura foi submetida ao influxo externo. Em seu texto, Schwarz cita uma passagem do manuscrito de Nestor Goulart Reis Filho em Arquitetura residencial brasileira no século XIX, descrevendo casas rurais na Província de São Paulo na segunda metade do século XIX:

\footnotetext{
Sobre as paredes de terra, erguidas por escravos, pregavam-se papeis decorativos europeus ou aplicavam-se pinturas, de forma a criar a ilusão de um ambiente novo, como os interiores das residências dos países em industrialização. Em certos exemplos, o fingimento atingia o absurdo: pintavam-se arquitetônicos greco-romanos - pilastras, arquitraves, colunatas, frisas etc. - com perfeição de perspectiva e sombreamento, sugerindo uma ambientação neoclássica jamais realizável com as técnicas e materiais disponíveis no local. Em outros, pintavam-se janelas nas paredes, com vistas sobre ambientes do Rio de Janeiro, ou da Europa, sugerindo um exterior longínquo, certamente diverso do real, das senzalas, escravos e terreiros de serviço." (SCHWARZ, 2012, p. 23)
}

A vida ideológica do país, mesmo após a sua independência, acompanhava os passos da Europa em direção à modernização e ao desenvolvimento do capital. O latifúndio escravista, fruto do capital comercial assim como o homem livre compunham o nosso cenário nacional, um cenário repleto de ambiguidades, retratado pelos romances de Machado de Assis que por sua vez traziam grande semelhança com a literatura russa por ser esta, também, resultado de uma 
ideologia estrangeira, como bem aponta Schwarz ao comparar o atraso histórico da Rússia ao atraso brasileiro. O fato é que, seja nos tempos da Independência, seja em pleno século XXI, sempre demos continuidade ao peso ideológico do estrangeiro. $\mathrm{Na}$ mídia, nos costumes, na economia de mercado, na teoria, no entretenimento, enfim, a vida brasileira parece ter sido e permanecer sendo constantemente permeada pelo influxo externo.

Em "Nacional por subtração", Roberto Schwarz inicia o texto da seguinte forma: "Brasileiros e latino-americanos fazemos constantemente a experiência do caráter postiç, inautêntico, imitado da vida cultural que levamos" (2012, p. 29). As ideias desencontradas e as inadequações vão desde shopping malls enfeitados com Papai Noel na neve em pleno nordeste árido brasileiro às teorias de autores estrangeiros que muitas vezes não se adequam a nossa realidade cultural, como se fossem uma vestimenta muito apertada para o nosso corpo. Schwarz chama a nossa atenção para o fato de as gerações de intelectuais brasileiros mais recentes insistirem em recomeçar do zero, sem levar em consideração críticos anteriores de nossa cultura, preferindo o discurso do outro, do estrangeiro, em busca de certo ineditismo. Assim, na crítica literária, assistimos o surgimento de diferentes correntes como o new criticism americano, a fenomenologia, o estruturalismo, o marxismo e tantas outras tendências de pensamento. $O$ resultado disto é o crescente fascínio pela crítica teórica estrangeira. Afinal, como analisar o texto literário de forma original sem cair nos ismos que por vezes incutam sentidos impróprios ao texto analisado? Em "Cuidado com as ideologias alienígenas", o crítico constata o fato de atualmente ser "muito mais fácil estar em dia com a bibliografia internacional do que com a realidade no Brasil. Esta última dificuldade não é só acadêmica. Se a experiência histórica de setores inteiros do país é atomizada e não soma, como conhecer todo o seu sentido?” (SCHWARZ, 2006, p. 52). De fato, cada vez mais somos direcionados à produção de um saber limitado e reduzido. Vivenciamos a união do isolamento e compartilhamos o conhecimento em pequenas unidades que, na maioria da vezes, segrega informações e referência em vez de integrar e abarcar o todo.

Um exemplo de crítica original que combate essa tendência reducionista do saber é encontrado na literatura brasileira e ressaltado por Schwarz. Trata-se do texto "Dialética da malandragem" de Antonio Candido. Ao refletir sobre a categoria do herói pícaro europeu, Candido compreende a inadequação desta categoria para analisar o herói da literatura brasileira. Observa que a classificação literária de pícaro não se encaixa devidamente em nossa cultura. Diferente da tendência para o real, como é evidenciado na narrativa pícara, o pretenso "pícaro" brasileiro tende para o ideal e para a realização de um final feliz. Em seu texto crítico Candido demonstra, através de sua análise detalhada do romance Memórias de um Sargento de Milícias (1854), a singularidade do herói de Manuel Antônio de Almeida, expondo cuidadosamente a formação do primeiro grande malandro no romance brasileiro. Diferentemente do pícaro europeu, o malandro na narrativa brasileira tem raízes no popular. Como bem ressalta Roberto Schwarz, Candido estabelece a dialética entre forma literária e processo social, ao descrever em detalhes como a organização da sociedade brasileira configura-se no romance de Manuel Antônio de Almeida. A análise do romance sob a nova perspectiva da "linha da malandragem" designa uma nova perspectiva teórica em categorizar o herói brasileiro sob o signo da astúcia e da "malandragem". Conforme Schwarz, esta malandragem vem desde os tempos do Brasil-colônia, ganha espaço na narrativa do século XIX com Memórias de um Sargento de Milícias e culmina com Macunaíma no século XX. A astúcia é o triunfo do nosso anti-herói. Através dela, o personagem transcende o real e reforça a originalidade da "teoria da malandragem" na narrativa brasileira. Em "Pressupostos, salvo engano, de "Dialética da malandragem"”, Schwarz reforça que "o influxo europeu não deixa naturalmente de ser "influência"” na literatura brasileira (2012, p. 149), no entanto, autores como Manuel Antonio de Almeida inovam no campo da forma e no conteúdo de sua literatura, o que impulsiona a crítica arguta de Candido.

Certamente não queremos de forma alguma afirmar aqui que as teorias estrangeiras sejam desnecessárias. Muito pelo contrário. Escritores como Machado de Assis, Mário de Andrade e 
Antonio Candido estiveram sempre abertos e bem informados quanto às novas teorias que surgiam, mas, para além delas, conseguiram retrabalhá-las e produzir sua própria crítica, com originalidade, sem se prender unicamente ao modelo estrangeiro.

O método crítico desses autores prima pelo duplo olhar - o de dentro e o de fora - num constante exercício de crítica dialética entre forma literária e processo social. Foi com base nesta composição dialética que estabelecemos uma ligação entre o verso "Oropa, França e Bahia" do poema de Ascenso Ferreira, retomando, portanto, o poema "Europa, França e Bahia", de Carlos Drummond, cujo título faz alusão à frase "Oropa, França e Bahia" contida na narrativa de Macunaíma, de Mário de Andrade. Assim temos a frase nos três textos, onde os três autores evidenciam o efeito do influxo externo na cultura brasileira com leveza e humor.

\section{Entre o sonho e o tédio: o olhar brasileiro em relação ao estrangeiro}

Iniciemos esta segunda parte com o poema de Ascenso Ferreira:

Oropa, França e Bahia

Para os 3 Manuéis:

Manuel Bandeira

Manuel de Sousa Barros

Manuel Gomes Maranbão

Num sobrado arruinado,

tristonho, mal assombrado,

que dava pros fundos da terra.

("Pra ver marujos,

Tirulilluliu!

quando vão pra guerra...”)

E dava fundos pro mar.

("Pra ver marujos,

Tiruliluliu!

ao desembarcar").

...Morava Manuel Furtado

português apatacado, com Maria de Alencar!

Maria era uma cafuza, cheia de grandes feitiços. Ah! os seus braços roliços! Ah! os seus peitos maciços! Faziam Manuel babar...

A vida de Manuel, que louco alguém o dizia, era vigiar das janelas toda a noite e todo o dia, as naus que ao longe passavam, de "Oropa, França e Bahia"!

- Me dá uma nau daquelas,

lhe suplicava Maria.

— Estás idiota, Maria.

Essas naus foram vintena

que eu herdei de minha tia! 
por todo o ouro do mundo eu jamais as trocaria!

Dou-te tudo o que quiseres: Dou-te xale de Tonquim! Dou-te uma saia bordada! Dou-te leques de marfim! Queijos da Serra da Estrela, perfumes de benjoim...

Nada.

A mulata só queria que Seu Manuel lhe desse uma nauzinha daquelas, inda a amais pichititinha, pra ela ir ver essas terras de "Oropa, França e Bahia”...

— Ó Maria, hoje nós temos vinhos da Quinta do Aguirre, umas queijadas de Sintra, só pra tu te distraíres desse pensamento ruim... - Seu Manuel, isso é besteira! Eu prefiro macaxeira com galinha de oxinxim!

"Ó lua que alumiais esse mundo do meu Deus alumia a mim também que ando fora dos meus..." Cantava Seu Manuel espantando os males seus.

"Eu sou mulata dengosa linda, faceira, mimosa, qual outras brancas não são"... Cantava forte Maria pisando fubá de milho, lentamente no pilão...

Uma noite de luar que estava mesmo taful, mais de 400 naus, surgiram vindas do Sul... - Ah, Seu Manuel, isto chega... Danou-se de escada abaixo, se atirou no mar azul.

— "Onde vais mulhé?" — "Vou me daná no carrossé!" — "Tu não vais, mulhé, mulhé, você não vai lá...”

Maria atirou-se n'água, Seu Manuel seguiu atrás... - Quero a mais pichititinha! - Raios te partam, Maria! Essas naus são meus tesouros, ganhou-as matando mouros 


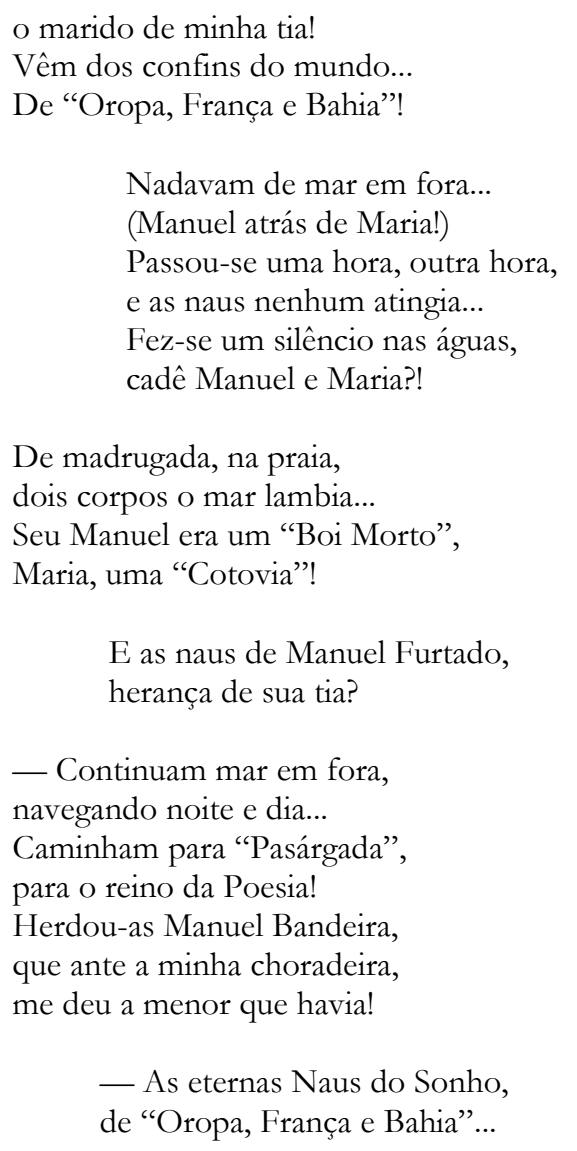

A narrativa poética de Ascenso Ferreira, "Oropa, França e Bahia”, do livro Xenhenhém, publicado em 1951, traz imagens que reforçam a sonoridade e a plasticidade nos versos. Misto de popular e erudito, o poema une a oralidade que representa parte da população brasileira pobre e iletrada ao discurso civilizado do colonizador português. O poema fortalece a linguagem do povo nordestino, povo este que, se não desfrutava de liberdade, agora, no poema, passa a ter liberdade nos versos livres de Ascenso. Além da espontaneidade do poeta pernambucano ao apresentar a nossa brasilidade e simplicidade, ressalta-se, também, o aspecto erudito de sua poesia. A técnica erudita unida ao ritmo popular evidencia a liberdade de criação da técnica do modernismo. Em termos formais, o poema possui dezoito estrofes diferentes - um terceto, um quinteto, quatro sextetos, quatro sétimas, uma oitava, dois quartetos, dois dísticos. Esta mistura de estrofes diferentes reforça a liberdade rítmica do poema. $\mathrm{O}$ autor procurou, ainda, aliar o modernismo ao regionalismo, aproximando o presente e o passado contidos nos versos. No poema destacamos a ingenuidade e a emoção da cafuza Maria em contraposição à rigidez e à praticidade do homem branco, o português Manuel.

O desfecho trágico no final do poema é resultado da teimosia de Maria em possuir uma das naus que admira toda noite de sua janela. As naus parecem ser uma alegoria do fascínio da população local pela novidade que chega do estrangeiro. Apesar de ser "cheia de grandes feitiços", Maria é quem passa a ser enfeitiçada pelas naus, tornando-se refém do seu sonho em possuir "uma nauzinha daquelas,/ inda a amais pichititinha, / pra ela ir ver essas terras / de "Oropa, França e Bahia". O poema retrata, portanto, a forte influência dos gostos e padrões vindos de terras estrangeiras. O olhar crítico de Ascenso Ferreira detecta esta influência externa sobre o Brasil, unindo humor e tragicidade no seu poema narrativo. Contudo, mesmo sob influência do influxo externo, por vezes Maria canta a sua terra, quando rejeita os "vinhos da Quinta do Aguirre" e "queijadas de Sintra", preferindo "macaxeira com galinha de oxinxim". 
Ao final do poema percebemos que, apesar da morte, Maria finalmente conseguirá alcançar uma das naus, não mais as naus estrangeiras, mas a nau-do-sonho, de um lugar que Manuel não tem permissão para entrar. As naus-do-sonho de Maria não se encontram além-mar, mas sim no reino da poesia, em Pasárgada, um reino mais próximo de terras brasileiras e de nossa brasilidade. Não por acaso Maria é comparada à "Cotovia" que, semelhante à poesia, é mediadora entre o ceú e a terra. Já o português Manuel é comparado a um "Boi Morto", um animal pesado, que dificilmente adentraria o domínio da poesia. A referência é clara ao poema "Boi Morto", de Manuel Bandeira.

"Europa, França e Bahia", de Carlos Drummond, apesar de semelhante título, traz um contexto diferente. Encontra-se em Alguma Poesia (1930), seu primeiro livro de poemas. Nessa obra o poeta mineiro oferece-nos rica lição geográfica e histórica. A ironia e a crítica em relação à Europa se fazem presentes. Através de um olhar cosmopolita ${ }^{4}$ seus versos revelam caricaturas dos países europeus, distorcendo a visão idealizada construída ao longo dos séculos. Leiamos o poema:

Europa, França e Bahia

Meus olhos brasileiros sonhando exotismos.

Paris. A torre Eiffel alastrada de antenas como um caranguejo.

Os cais bolorentos de livros judeus

e a água suja do Sena escorrendo sabedoria.

O pulo da Mancha num segundo.

Meus olhos espiam olhos ingleses vigilantes nas docas.

Tarifas bancos fábricas trustes craques.

Milhões de dorsos agachados em colônias longínquas formam um tapete [para sua Graciosa Majestade Britânica pisar.

$\mathrm{E}$ a lua de Londres como um remorso.

Submarinos inúteis retalham mares vencidos.

O navio alemão cauteloso exporta dolicocéfalos arruinados.

Hamburgo, umbigo do mundo.

Homens de cabeça rachada cismam em rachar a cabeça dos outros

[dentro de alguns anos.

A Itália explora conscienciosamente vulcões apagados,

vulcões que nunca estiveram acesos

a não ser na cabeça de Mussolini.

E a Suíça cândida se oferece

numa coleção de postais de altitudes altíssimas.

Meus olhos brasileiros se enjoam da Europa.

Não há mais Turquia.

O impossível dos serralhos esfacela erotismos prestes a deslanchar.

Mas a Rússia tem as cores da vida.

A Rússia é vermelha e branca.

Sujeitos com um brilho esquisito nos olhos criam o filme bolchevista e no [túmulo de Lenin em Moscou parece que

mas não bate igual ao da gente... [um coração enorme está batendo, batendo

\footnotetext{
3 “Boi Morto" é o primeiro poema do penúltima livro de poemas, Opus 10, de Manuel Bandeira.

${ }^{4}$ Em sua "Introdução à leitura dos poemas de Carlos Drummond de Andrade", Silviano Santiago explica que a visão cosmopolita do poeta mineiro é adquirida "na experiência da viagem-pela-leitura" e que não deve ser confundida com a experiência empírica do deslocamento a outros países.
} 


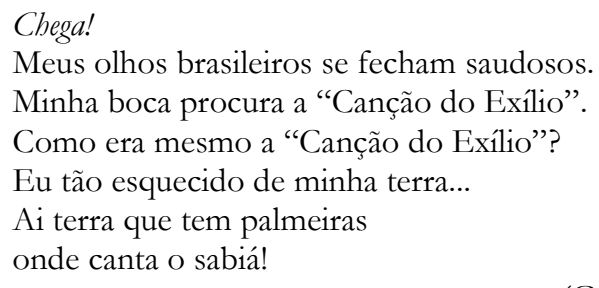

(Grifos nossos)

É mister ressaltar o estilo paródico e a acidez contida na poética drummondiana. Os "olhos brasileiros" desiludidos enxergam as cidades descritas através da lente do humor aliada à ironia do poeta. As contradições presentes nos símiles escolhidos na primeira estrofe, por exemplo, revelam uma Paris despida de toda a pompa, afinal, a torre Eiffel leva como símile o "caranguejo", enquanto que o famoso rio Sena, ainda que escorra "sabedoria", possui sua água "suja". Em lugar da admiração e do aparvalhamento dos turistas diante da paisagem estrangeira, o eu-poético revela a sensação de tédio, o cansaço na alma e o peso no coração.

$\mathrm{Na}$ terceira estrofe temos a lua de Londres que olha com remorso por ser cúmplice da submissão das colônias que servem como tapete para a "Graciosa Majestade Britânica pisar". Já na quarta estrofe, temos a previsão do que viria a acontecer anos depois, na II Guerra Mundial. A estrofe expõe os alemães como "homens de cabeça rachada" que "cismam em rachar a cabeça dos outros/ dentro de alguns anos." Não só a Alemanha, mas também a Itália de Mussolini é mencionada na quinta estrofe, que inclui, ainda, a neutralidade e a indiferença da Suíça que observava o cenário da Guerra de suas "altitudes altíssimas", quiçá com o mesmo remorso da lua de Londres.

O poema apresenta um amadurecimento da percepção/olhar do eu-lírico. Observemos que na primeira estrofe temos: "Meus olhos brasileiros sonhando exotismos", como se a Europa fosse um lugar de sonho e esplendor para o viajante. Contudo, este olhar do poeta viajante não é passivo, pois questiona a imagem cristalizada que recebemos do continente europeu. Se no início do poema os olhos eram sonhadores, depois eles passam a olhos que espiam outros olhos, como vemos na segunda estrofe. Mais adiante, na metade do poema, temos o verso: "Meus olhos brasileiros se enjoam da Europa." O sonho passa a ser substituído pelo tédio, pelo enjoo diante da paisagem europeia.

A penúltima estrofe, apesar das "cores da vida" exibidas pelos russos - "A Rússia é vermelha e branca" -, o eu-poético alerta para o "brilho esquisito" nos olhos de uma população comandada por ideologias, como é retratado no clássico filme de Eisenstein sobre a revolução bolchevique. A estrofe termina com a constatação de que o coração russo "não bate igual ao da gente", simplesmente porque tivemos outra história, cujo enredo não é o mesmo do contexto de outros países. Não deveríamos, portanto, importar ideologias e nem olhar o mundo através das lentes estrangeiras.

A brasilidade no final do poema é resgatada como um alívio diante do excesso do influxo externo vivenciado pelo eu-poético. Vemos que os "olhos brasileiros" conseguem recriar, de forma poética, a Europa que nos colonizou. De forma criativa e jocosa o poeta utilizou imagens para compor caricaturas da França, Inglaterra, Alemanha, Itália, Suíça e Rússia.

Finalmente o eu-lírico desabafa com um "Chega!" na última estrofe, sentindo-se saudoso do Brasil e tentando se lembrar do poema de Gonçalves Dias: "Meus olhos brasileiros se fecham saudosos. /Minha boca procura a "Canção do Exílio"”.

A frase "Oropa, França e Bahia", ilustrada nos poemas de Ascenso Ferreira e Carlos Drummond, já se encontrava em Macunaíma: o herói sem nenhum caráter (1927), como mostra o seguinte trecho: 


\begin{abstract}
- Meu genro: você carece de casar com uma das minhas filhas. O dote que dou pra ti é Oropa França e Babia. Mas, porém você tem que ser fiel e não andar assim brincando com as outras cunhãs por aí.

Macunaíma agradeceu e prometeu que sim jurando pela memória da mãe dele. Então Vei saiu com as três filhas pra fazer o dia no cerradão, ordenando mais uma vez que Macunaíma não saísse da jangada pra não andar brincando com as outras cunhas por aí. Macunaíma tornou a prometer, jurando outra vez pela mãe.

(ANDRADE, 2016, p. 46) (Grifo nosso)
\end{abstract}

No intuito de subverter a ordem existente, artistas da década de 20 combateram os formalismo parnasiano e buscaram expressar uma nova poética. Dentre esses artistas destacaramse Manuel Bandeira, Mário de Andrade e Oswald de Andrade. Experimentando um momento de nacionalismo estético e pitoresco, com o objetivo de encontrar a representação e a caracterização de ser brasileiro, Mário de Andrade cria o anti-herói Macunaíma. Este passa a ser considerado um sujeito sem caráter, não no sentido unicamente moral, mas, sobretudo, no sentido de não possuir civilização própria. Por isso o personagem apresenta-se em constante metamorfose. Seu perfil é justamente não ter um perfil definido. Macunaíma não apresenta valores morais nem culturais, seja do branco, do índio ou do negro. Ele é caracterizado pela multiplicidade, representando dessa forma a nação brasileira em constante processo de elaboração.

Em A República Mundial das Letras (2002), no subcapítulo "Macunaíma o anti-Camões", Pascale Casanova identifica a narrativa de Mário de Andrade como o manifesto fundador de uma literatura nacional e a busca por uma cultura própria do Brasil. A autora analisa três pontos importantes: o rompimento com a dependência linguística/literária de Portugal, o fim da dominação europeia, e o equívoco da crítica do lugar-comum em rotular Macunaíma um mero preguiçoso. A autora sustenta que a literatura por si só já é um discurso político, consciente, ideológico. Os autores, assim como os próprios críticos de literatura, têm consciência dos complexos mecanismos e leis que regem o labor da escrita. Casanova oferece um novo método interpretativo, baseando-se no jogo das desigualdades para analisar as relações entre dominados e dominantes e a quebra das hierarquias literárias, na tentativa de realizar uma discussão na República Mundial das Letras, buscando uma construção do espaço literário próprio. Como sabemos, as primeiras potências literárias reconhecidas foram Itália, França, Alemanha, Espanha e Inglaterra. Com o processo de descolonização, os países até então excluídos reivindicaram o acesso à legitimidade e à existência literárias. A reivindicação de nossa identidade nacional ocorre a partir do rompimento do "modernismo" dos anos 20, e tem continuidade por meio de escritores que ao abordarem o externo, privilegiam o cotidiano e o folclore brasileiros. Observamos essa autenticidade artística de contrapor o externo ao interno nos exemplos das naus portuguesas do poema de Ferreira, na Europa apresentada pelo olhar de Drummond, e na recusa do autor de Macunaíma em repetir a língua de Camões.

\title{
CONSIDERAÇÕES FINAIS
}

Por meio da crítica de Candido, Schwarz e Casanova percebemos a reponsabilidade e o empenho desses autores em evidenciar a nossa dependência cultural como uma fatalidade histórica. Isso ocorre devido a uma má interpretação de nossa realidade. É preciso, portanto, ter cuidado para não sermos seduzidos por teorias, conceitos e referências estrangeiras que, na verdade, se adequam a outros processos sociais, completamente diferentes do nosso.

Nos textos literários aqui comentados vimos a perfeita sintonia entre Carlos Drummond, Ascenso Ferreira e Mário de Andrade ao expressarem o seu entendimento do nacional frente ao estrangeiro. O uso da paródia revela-se uma forma de crítica e naturalmente explicita o efeito do influxo externo na cultura brasileira. 
Somado aos "olhos brasileiros" desses escritores, temos o olhar da crítica arguta de Schwarz sobre o efeito do influxo externo em nossa cultura. E como definiríamos a cultura de nosso país? Como caracterizaríamos o ser brasileiro? Vimos que os textos literários e críticos comentados neste breve ensaio terminaram por alcançar o ser brasileiro às avessas, pois é descrevendo aquilo que vemos do lado de fora que melhor enxergamos o nosso lado de dentro. Como bem afirma Benjamin Abdala Junior, "para Antonio Candido, a situação histórico-cultural (isto é, os fatores externos) tornam-se internos na realização textual. A formas literárias são assim históricas e sociais, sem deixarem de ter sua autonomia específica - uma autonomia relativa capaz de articular o social e o histórico" (2006, p. 218). Assim, os textos literários elucidados neste ensaio revelam impressões, ideias e experiências dos autores com um tom satírico em relação à influência estrangeira

Por fim, gostaríamos de concluir com as palavras de Candido em seu texto "Sobre Roberto Schwarz". Ao confirmar a precisão analítica de Schwarz, o autor destaca o quão eficaz e coerente é o seu método de análise ao integrar o estruturalismo à crítica sociologia, destacandose, portanto, como um ensaísta que produziu mudanças significativas na crítica brasileira. Sua crítica situa-se dentro e fora do texto, dentro e fora do Brasil. Conforme Candido, Schwarz

teve desde sempre como próprias a língua e a cultura alternativas que precisamos adquirir com esforço. Isso lhe permite ver o Brasil como quem é de dentro e de fora por natureza, o que produz uma combinação sui generis de estranhamento e familiaridade, a qual deve ter contribuído para o cunho singular da sua lucidez analítica" (2007, p. 16).

\section{REFERÊNCIAS BIBLIOGRÁFICAS}

ABDALA JUNIOR, Benjamin. Formação da Literatura Brasileira, de Antonio Candido. In: CARA, Salete de Almeida \& ABDALA, Benjamin (orgs.) Moderno de nascença: figurações críticas do Brasil. São Paulo: Boitempo, 2006.

ANDRADE, Carlos Drummond de. Alguma poesia. São Paulo: Companhia das Letras, 2013.

ANDRADE, Mário de. Macunaíma: o herói sem nenhum caráter. Rio de Janeiro: Martin Claret, 2016.

CANDIDO, Antonio. Dialética da malandragem. In: . O discurso e a cidade. São Paulo: Duas Cidades, 1993.

CANDIDO, Antonio. Sobre Roberto Schwarz. In: CEVASCO, Maria Elisa; OHATA, Milton (orgs). Um crítico na periferia do capitalismo: reflexões sobre a obra de Roberto Schwarz. São Paulo: Companhia das Letras, 2007.

CARA, Salete de Almeida \& ABDALA, Benjamin (orgs.) Moderno de nascença: figurações críticas do Brasil. São Paulo: Boitempo, 2006.

CASANOVA, Pascale. A República Mundial das Letras. São Paulo: Estação Liberdade, 2002.

FERREIRA, Ascenso. Catimbó, Cana-Caiana, Xenhenhém. São Paulo: Martins Fontes, 2008. 
SANTIAGO, Silviano. Introdução à leitura dos poemas de Carlos Drummond de Andrade. In: ANDRADE, Carlos Drummond de. Poesia completa. Rio de Janeiro: Nova Aguilar, 2003.

SCHWARZ, Roberto. Nacional por subtração. Pressupostos, salvo engano, de "Dialética da malandragem". In: Que horas são?: ensaios. São Paulo: Companhia das Letras, 2012.

SCHWARZ, Roberto. Cuidado com as ideologias alienígenas. In: CARA, Salete de Almeida \& ABDALA, Benjamin (orgs.) Moderno de nascença: figurações críticas do Brasil. São Paulo: Boitempo, 2006.

SCHWARZ, Roberto. As ideias fora do lugar. In: Ao vencedor as batatas: forma literária e processo social nos inicios do romance brasileiro. São Paulo: Livraria Duas Cidades, Editora 34, 2012. 